\title{
Nusinersen Treatment in Adults With Spinal Muscular Atrophy
}

Tina Duong, PT, PhD, Connie Wolford, MSN, FNP-BC, Michael P. McDermott, PhD, Chelsea E. Macpherson, PT, DPT, NCS, Amy Pasternak, PT, DPT, PCS, Allan M. Glanzman, PT, DPT, PCS, William B. Martens, BA, Elizabeth Kichula, MD, BA, Basil T. Darras, MD, Darryl C. De Vivo, MD, Zarazuela Zolkipli-Cunningham, MBChB, MRCP, Richard S. Finkel, MD, Michael Zeineh, MD, PhD, Max Wintermark, MD, Jacinda Sampson, MD, PhD, Katharine A. Hagerman, PhD, Sally Dunaway Young, PT, DPT, and John W. Day, MD, PhD on behalf of the Stanford Neuromuscular Coordinating Center

Neurology: Clinical Practice June 2021 vol. 11 no. 3 e317-e327 doi:10.1212/CPJ.0000000000001033
Correspondence

Dr. Duong

trduong@stanford.edu

\section{Abstract}

\section{Objective}

To determine changes in motor and respiratory function after treatment with nusinersen in adults with spinal muscular atrophy (SMA) during the first two years of commercial availability in the USA.

\section{Methods}

Data were collected prospectively on adult (age $>17$ years at treatment initiation) SMA participants in the Pediatric Neuromuscular Clinical Research (PNCR) Network. Baseline assessments of SMA outcomes including the Expanded Hammersmith Functional Rating Scale (HFMSE), Revised Upper Limb Module (RULM), and 6-Minute Walk Test (6MWT) occurred $<5$ months before treatment, and post-treatment assessments were made up to 24 months after nusinersen initation.

Patient-reported experiences, safety laboratory tests and adverse events were monitored. The mean annual rate of change over time was determined for outcome measures using linear mixed effects models.

\section{Results}

Forty-two adult SMA participants (mean age: 34 years, range 17-66) receiving nusinersen for a mean of 12.5 months (range 3-24 months) were assessed. Several motor and respiratory measures showed improvement distinct from the progressive decline typically seen in untreated adults. Participants also reported qualitative improvements including muscle strength, stamina, breathing and bulbar related outcomes. All participants tolerated nusinersen with normal surveillance labs and no significant adverse events.

\section{Conclusions}

Trends of improvement emerged in functional motor, patient-reported, and respiratory measures, suggesting nusinersen may be efficacious in adults with SMA. Larger well-controlled studies and additional outcome measures are needed to firmly establish the efficacy of nusinersen in adults with SMA.
MORE ONLINE

$\rightarrow$ Class of Evidence

Criteria for rating therapeutic and diagnostic studies

NPub.org/coe 


\section{Classification of Evidence}

This study provides Class IV evidence regarding nusinersen tolerability and efficacy based on reported side effects and pulmonary and physical therapy assessments in an adult SMA cohort.

Spinal muscular atrophy (SMA) is an autosomal recessive disorder affecting 1: 7,000-11,000 live births. ${ }^{1,2}$ In SMA, survival motor neuron (SMN) protein deficiency leads to motor neuron dysfunction and degeneration, causing progressive muscle atrophy, weakness, and early mortality. ${ }^{3,4}$ SMN protein is produced by $S M N 1$ and $S M N 2$ genes, with pathogenicity occurring only with no functional copies of SMN1. SMN2 generates protein less efficiently, but increased SMN2 gene copy number increases SMN protein and decreases disease severity. ${ }^{5,6}$

Nusinersen is an antisense oligonucleotide that modifies SMN2 RNA splicing, increasing protein production. ${ }^{7,8}$ Nusinersen was effective at improving motor function and survival in infantile- and childhood-onset $\mathrm{SMA}^{9-15}$ leading to US Food and Drug Administration (FDA) approval in December 2016 for SMA in all ages. Notably, at the time of its approval, trials of nusinersen did not include adults.

Understanding of infantile- and childhood-onset SMA has progressed rapidly because of molecular confirmation of the diagnosis coupled with multicenter natural history studies that enabled stratification by age, functional ability, and rate of change. ${ }^{10,11,16-20}$ Older, more chronically affected patients vary in functional ability and disease course, and tolerate fewer assessments without considerable fatigue, making research more difficult. An inverse relationship between motor function and disease progression for ages $>15^{20}$ and $>20$ years ${ }^{21}$ have been described in treatment-naive adults.

This is a case series of SMA adults in whom nusinersen was initiated. We report motor and respiratory changes before and after nusinersen treatment to better understand possible treatment effects.

\section{Methods}

This study is part of a multisite longitudinal study of SMA. Data were collected based on initial functional status for all individuals in the study (figure 1). As part of the medical history, we also obtained information on surgical history, medications, SMA type (historically highest functional level achieved), age at diagnosis, disease duration, SMN2 copy number, and current functional status.

\section{Standard Protocol Approvals, Registrations, and Patient Consents}

Data were collected prospectively through an IRB-approved study conducted by the Pediatric Neuromuscular Clinical Research (PNCR) Network on all nusinersen-treated adults (age $\geq 17$ years at the start of treatment) at participating centers with genetic confirmation and clinical symptoms of SMA. Forty-two participants provided informed consent before evaluations. Data were collected from January 2017 to March 2019. The purpose was to evaluate changes in clinical outcome measures and to obtain safety information related to nusinersen treatment.

Clinical assessments were performed approximately every 4 months during clinic visits. Intrathecal loading doses of 12 $\mathrm{mg}$ of nusinersen were given based on the recommended schedule (baseline, day 14 , day 28 , day 58 , and every 4 months thereafter). Safety laboratory tests performed before injection included platelet count, prothrombin time, partial thromboplastin time, and urine protein.

\section{Clinical Evaluations}

Clinical outcomes were obtained during clinic visits using a minimal data set determined by the PNCR network based on participant functional status as well as insurance requirements (figure 1). Clinical evaluators were physical therapists with consistent training in the PNCR network and other clinical trials to administer the outcome measures. The same evaluator was used for most visits throughout the time frame of data collection. Clinical outcome measures were selected based on previous natural history studies in SMA and their

Figure 1 Clinical Outcomes Based on Functional Groups

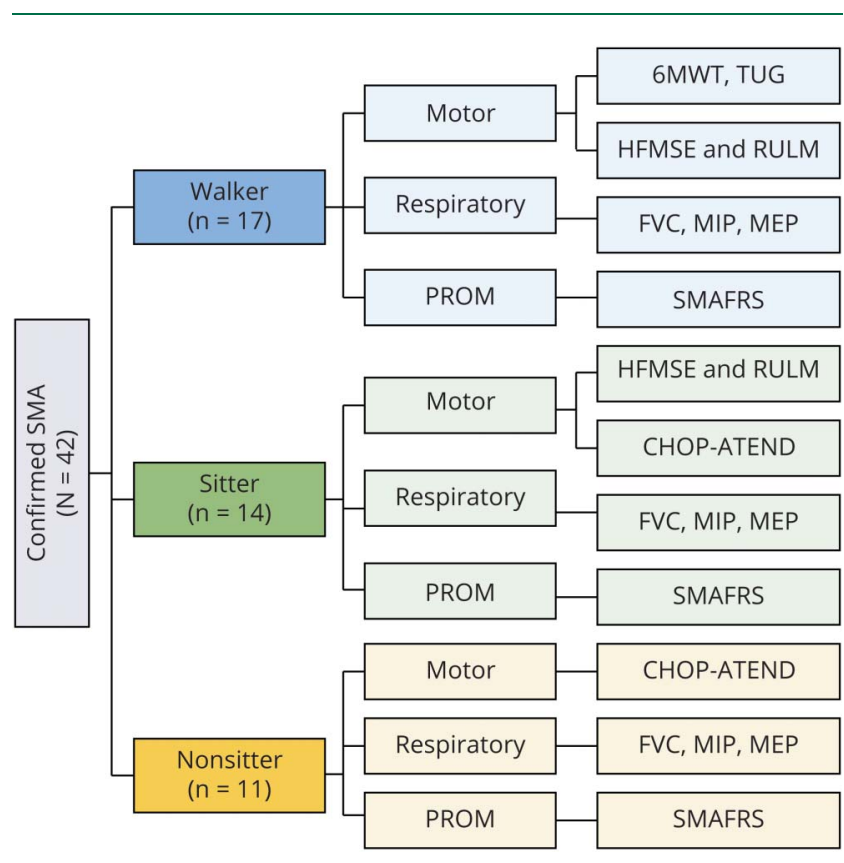

6MWT = 6-minute walk test; CHOP-ATEND = Children's Hospital of Philadelphia's Adult Test of Neuromuscular Disorders; FVC = forced vital capacity; HFMSE = Expanded Hammersmith Functional Motor Scale; MEP = maximal expiratory pressure; MIP = maximal inspiratory pressure; PROM = patientreported outcome measure; RULM = revised upper limb module; SMAFRS = Spinal Muscular Atrophy Functional Rating Scale; TUG = timed up and go. 
sensitivity of assessment to detect change. Validated motor outcomes in SMA were selected for each participant based on the participant's baseline functional status: Walker (able to take 5 steps independently), sitter (able to sit independently for 3 seconds without support), and nonsitter (unable to sit independently) (figure 1).

The Children's Hospital of Philadelphia Adult Test of Neuromuscular Disorders (CHOP-ATEND) used in this study was a new scale modified from the original Children's Hospital of Philadelphia Infant Test of Neuromuscular Disorders (CHOP-INTEND) and excluded items that cannot be performed with adults (items 11,15 , and 16). ${ }^{24} \mathrm{Be}-$ cause the CHOP-INTEND was a scale designed to assess infants with SMA type $1,{ }^{25}$ there were minimal considerations in the manual for the impact of contractures on scoring. With adults, contractures have greater influence on test administration and evaluation of results; therefore, criteria for start positions, contracture considerations, and grading methodology were clarified while keeping the construct of the items intact. The Spinal Muscular Atrophy Functional Rating Scale (SMAFRS), ${ }^{26}$ a patient-reported outcome measure, and pulmonary function tests of forced vital capacity (FVC), maximal inspiratory pressure (MIP), and maximal expiratory pressure (MEP) were performed in all functional groups. The Hammersmith Functional Motor Scale Expanded (HFMSE), ${ }^{27}$ Revised Upper Limb Module (RULM) ${ }^{28}$ 6-minute walk test (6MWT), and timed up and go (TUG $)^{29}$ were performed using standardized reliable methods established by the PNCR Network. ${ }^{16,17}$

\section{Statistical Analysis}

Five participants did not have clinical evaluations coincident with nusinersen initiation; therefore, the most recent evaluations before starting nusinersen, all within 5 months of the first dose, were used as the pretreatment value in the analyses. All data collected after nusinersen initiation were also included. Linear mixed-effects models were used to estimate the mean annual rate of change (slope) for each outcome. This was done for the cohort of all participants as well as by subgroups defined by SMA type (2 and 3), SMN2 copy number (3 and 4), functional status (nonsitter, sitter, and walker), and history of spinal surgery. The model for estimating the overall mean slope included time after nusinersen initiation (continuous, expressed in years) with random intercept and slope coefficients. To estimate mean slopes in subgroups, the above model was expanded to include the appropriate main effect and interaction terms (e.g., SMA type and the interaction between SMA type and year).

\section{Data Availability}

Deidentified data may be shared with any qualified investigator on request. Data can be requested by all interested stakeholders for clinical research and trial planning. Data requests are reviewed by the PNCR Steering Committee, which can be contacted via the corresponding author.

\section{Results}

The 42 nusinersen-treated participants were adults with SMA type 2 or type 3 (table 1 ) who were treated for a range of 3-24 months (mean treatment duration 12.5 months). The mean age at treatment initiation was 33.7 years (range 17.7-66.1 years), $57 \%$ were male, and $62 \%$ had 3 copies of the SMN2 gene. The distribution of functional status was nonsitter $(n=17)$, sitter $(n=14)$, and walker $(n=11)$ (table 1). A broad spectrum of function was represented at baseline, with a median HFMSE score of 19.0 (range 0-60) and a mean RULM score of 18.2 (range 0-37) (table 1).

A total of 306 injections were performed. Procedure approaches were all through lumbar access with 155 traditional blind lumbar punctures (LPs), 136 fluoroscopy guided LPs, and 15 LPs requiring CT guidance. An interlaminar lumbar approach took place in all but $2.3 \%$ that required a transforaminal approach. Four patients discontinued treatment: 1 for personal reasons despite continued successful injections, 2 for a combination of insurance limitations and lack of perceived ongoing effectiveness, and 1 due to bony overgrowth at the only thecal access site. Of these patients who discontinued treatment, 3 had treatment for 18 months and 1 for 10 months.

Overall, nusinersen was well tolerated with 2 reported cases of mild thrombocytopenia (platelet counts between 100,000 and $150,000)$ that resolved spontaneously and 3 cases of transient limb pain not directly related to the injection procedure that resolved within a few months. Adverse events were rare, mild, and transient and did not warrant discontinuation of therapy. The most common adverse event post-LP was transient headache that in all cases resolved spontaneously. This occurred following 16 of 234 injections (6.8\%) and affected 6 patients (14.3\%), an incidence comparable to that in other studies using atraumatic needles to reduce post-LP headaches. ${ }^{30,31}$ Other infrequently reported adverse events included injection site pain, nausea/ vomiting, lightheadedness, and anxiety. No cases of hydrocephalus, bleeding/bruising, or renal compromise were identified. All adverse events resolved quickly without intervention.

Table 2 shows the mean annual rates of change (slopes) with corresponding 95\% confidence intervals (CIs) for all participants. Notably, all mean slopes were in a positive direction, although some were accompanied by wide CIs. For the motor measures, the most prominent improvement was seen with the CHOPATEND (mean slope $=3.59$ points/year, 95\% CI 0.67-6.51, figure 2) and the SMAFRS (mean slope $=1.44$ points $/$ year, $95 \%$ CI 0.04-2.83, $p=0.04$ ). Improvements in the CHOP-ATEND were most noticeable in those with more severe phenotypes (SMA type 2, nonsitters, and those with 3 SMN2 copies; table 3 ). In the small subset of participants who performed the TUG test $(\mathrm{n}=8)$, the mean slope on the log scale was $-0.10(95 \%$ CI -0.21 to 0.01 ) with a negative value indicating improvement in the time to complete this task. To interpret this on a time scale (seconds), exponentiating these values reveals that, on average, the time to 
Table 1 Clinical Characteristics

\begin{tabular}{ll}
\hline Variable & \\
\hline Age (y); mean (SD), range & $33.7(12.6), 17.7$ to 66.1 \\
\hline Age at onset (mo); median, range & $18.0,3.0$ to 180.0 \\
\hline Disease duration (y); mean (SD), range & $30.9(12.3), 12.1$ to 60.6 \\
\hline Sex; N (\%) & $24(57.1)$ \\
\hline Male & $18(42.9)$ \\
\hline Female & $1(2.8)$ \\
\hline SMN2 copy number; N (\%) ${ }^{\mathbf{a}}$ & $26(72.2)$ \\
\hline 2 & $9(25.0)$ \\
\hline 3 & \\
\hline $\mathbf{4}$ & $8(19.1)$ \\
\hline SMA type ${ }^{22}$; $(\%)^{\mathbf{b}}$ & $10(23.8)$ \\
\hline 2A & $12(28.6)$ \\
\hline 2B & $12(28.6)$ \\
\hline 3A & \\
\hline 3B & \\
\hline
\end{tabular}

Functional status at baseline; $\mathrm{N}(\%)$

\begin{tabular}{lc}
\hline Nonsitter & $17(40.5)$ \\
\hline Sitter & $14(33.3)$ \\
\hline Walker & $11(26.2)$
\end{tabular}

Spinal fusion; N (\%)

\begin{tabular}{|c|c|}
\hline Yes & $16(38.1)$ \\
\hline No & $26(61.9)$ \\
\hline HFMSE: median, range $(n=39)$ & 19,0 to 60 \\
\hline RULM: mean (SD), range $(n=41)$ & $18.2(14.0), 0$ to 37 \\
\hline CHOP-ATEND: mean (SD), range $(n=26)$ & $23.4(12.1), 5$ to 42 \\
\hline $\begin{array}{l}\text { 6MWT distance }(m) \text { : mean }(S D), \\
\text { range }(n=10)\end{array}$ & $300.2(123.8), 69$ to 466 \\
\hline TUG (s): median, range $(n=8)$ & $10.0,8.4$ to 44.7 \\
\hline SMAFRS: median, range $(n=33)$ & $15.0,0$ to 49 \\
\hline FVC (\%): mean (SD), range $(n=31)$ & $61.5(33.0), 9$ to 112 \\
\hline MEP $\left(\mathrm{cm} \mathrm{H}_{2} \mathrm{O}\right)$ : mean $(\mathrm{SD})$, range $(n=29)$ & $50.6(26.8), 11$ to 97 \\
\hline MIP $\left(\mathrm{cm} \mathrm{H}_{2} \mathrm{O}\right)$ : mean $(\mathrm{SD})$, range $(n=29)$ & $-79.8(44.0),-174$ to -8 \\
\hline
\end{tabular}

Abbreviations: $6 \mathrm{MWT}=6$-minute walk test; $\mathrm{CHOP}=$ Children's Hospital of Philadelphia; CHOP-ATEND = Children's Hospital of Philadelphia Adult Test for Neuromuscular Disorders; $\mathrm{Cl}=$ confidence interval; $\mathrm{FVC}=$ forced vital capacity; HFMSE = Hammersmith Functional Motor Scale Expanded; $\mathrm{MEP}=$ maximal expiratory pressure; MIP = maximal inspiratory pressure; RULM = revised upper limb module; SMA = spinal muscular atrophy; SMAFRS = Spinal Muscular Atrophy Functional Rating Scale; SMN2 = survival motor neuron 2; TUG = timed up and go.

${ }^{a}$ SMN2 copy number was missing in 6 subjects.

b $2 \mathrm{~A}=$ able to sit unsupported and no ability to stand or walk with help; $2 \mathrm{~B}=$ able to sit unsupported and able to stand or walk with help; $3 A=$ able to walk independently and symptom onset $\leq 36 \mathrm{mo}$ of age; $3 \mathrm{~B}=$ able to walk

independently and symptom onset $>36 \mathrm{mo}$ of age. perform the TUG test at 1 year was 0.90 (or 90\%) of that at baseline (95\% CI 0.81-1.01).

There was a wide range of ventilatory function among participants (table 1). Overall, respiratory measures exhibited a mean rate of change indicating potential improvement after nusinersen treatment (table 2 ), most prominently with respiratory muscles of MEP (mean slope $=6.38 \mathrm{~cm} \mathrm{H}_{2} \mathrm{O}$ /year, 95\% CI 2.52-10.25) and to a lesser extent MIP (mean slope $=-5.50 \mathrm{~cm} \mathrm{H}_{2} \mathrm{O}$ per year, $95 \% \mathrm{CI}-11.47$ to 0.47 ).

Subcohort analyses were also performed to better understand the influence of SMN2 copy numbers (table 3). In our study, 9 individuals had 4 copies of SMN2, 2 of whom were female. We found broad heterogeneity in this cohort with 2 nonsitters, 2 sitters, and 5 ambulatory participants with age ranging from 26.7 to 65.5 years. All were diagnosed as SMA type 3 except 1 being SMA type 2, and disease duration ranged from 12 months to 15 years. This range in phenotypes and small sample size explains the variation in rates of change seen in the outcome measures.

\section{Discussion}

This study is a prospective observational study of adults with SMA treated with nusinersen in the real-world setting. Results indicate that nusinersen is safe and tolerable in a heterogeneous group of adults with SMA types 2 and 3 ranging from ages 17 to 66 years. Participants of this study were not included in the 2 pivotal clinical trials of nusinersen and began treatment after FDA approval of nusinersen.

Participants in this study have reported common subjective improvements that are consistent with those of recent reports ${ }^{31-33}$ including greater active range of motion in the fingers and hands; louder voice; and improved jaw movement and speech, which differ from reported natural history of progressive bulbar dysfunction and decreased mouth opening associated with fatty degeneration of the lateral pterygoid muscles. ${ }^{34}$ These gains are consistent with a previous study of older individuals with SMA in which 8 of 12 individuals had similar improvements in upper limb and head movement. $^{33}$

Although limited natural history data in SMA are available for the TUG, ${ }^{29}$ SMAFRS, ${ }^{26}$ and the respiratory measures including MIP and MEP, ${ }^{35}$ our data in adults treated with nusinersen diverge from the expected progressive course of the disease. ${ }^{16,35}$ Further data collection and validation will be helpful to determine the utility of these measures in monitoring response to treatment.

Clinical evaluations performed were based on baseline functional status of the participants (figure 1). For this reason, all 42 participants did not receive the same evaluations. The HFMSE was performed on some nonsitters showing a floor effect of 
Table 2 Average Rates of Change per Year in Outcome Measures

\begin{tabular}{|c|c|c|c|}
\hline Outcome & $\mathrm{N}$ & Slope $^{a}$ & $95 \% \mathrm{Cl}$ \\
\hline HFMSE & 31 & 0.86 & (-0.52 to 2.24$)$ \\
\hline RULM & 39 & 0.11 & $(-0.45$ to 0.67$)$ \\
\hline CHOP-ATEND & 24 & 3.59 & (0.67 to 6.51 ) \\
\hline 6MWT distance (m) & 10 & 3.29 & ( -28.04 to 34.62$)$ \\
\hline Log [TUG (s)] & 8 & $-0.10^{b}$ & $(-0.21$ to 0.01$)$ \\
\hline SMAFRS & 31 & 1.44 & (0.04 to 2.83 ) \\
\hline FVC (\%) & 27 & 0.75 & $(-1.87$ to 3.38$)$ \\
\hline $\operatorname{MEP}\left(\mathrm{cm} \mathrm{H} \mathrm{H}_{2} \mathrm{O}\right)$ & 25 & 6.38 & (2.52 to 10.25 ) \\
\hline MIP $\left(\mathrm{cm} \mathrm{H}_{2} \mathrm{O}\right)$ & 26 & $-5.50^{b}$ & $(-11.47$ to 0.47$)$ \\
\hline
\end{tabular}

Abbreviations: 6MWT $=6$-minute walk test; CHOP-ATEND = Children's Hospital of Philadelphia Adult Test for Neuromuscular Disorders; $\mathrm{Cl}=$ confidence interval; FVC = forced vital capacity; HFMSE = Hammersmith Functional Motor Scale Expanded; MEP = maximal expiratory pressure; MIP = maximal inspiratory pressure; RULM = revised upper limb module; SMAFRS = Spinal Muscular Atrophy Functional Rating Scale; TUG = timed up and go.

a Slope is expressed as the unit change in outcome per year.

${ }^{\mathrm{b}}$ The negative slopes for TUG and MIP are consistent with functional improvements in those measures.

only being able to complete 2 items (hip and knee flexion when supine). For those who had a CHOP-ATEND assessment alongside the RULM or HFMSE assessment, 90.9\% (10/11) individuals had a floor effect (score of 0 ) on the HFMSE and $54.5 \%(6 / 11)$ had a floor effect (score of 0$)$ on the RULM. We were able to capture a broader range of motor abilities in those who were weaker with the CHOP-ATEND score, which ranged from 5 to 28 .

The mean HFMSE rate of change did not differ substantially among the functional groupings in a natural history study and was fairly consistent with estimated decline between 0.5 and 1 points

Figure 2 Average Annual Rate of Change in CHOP-ATEND

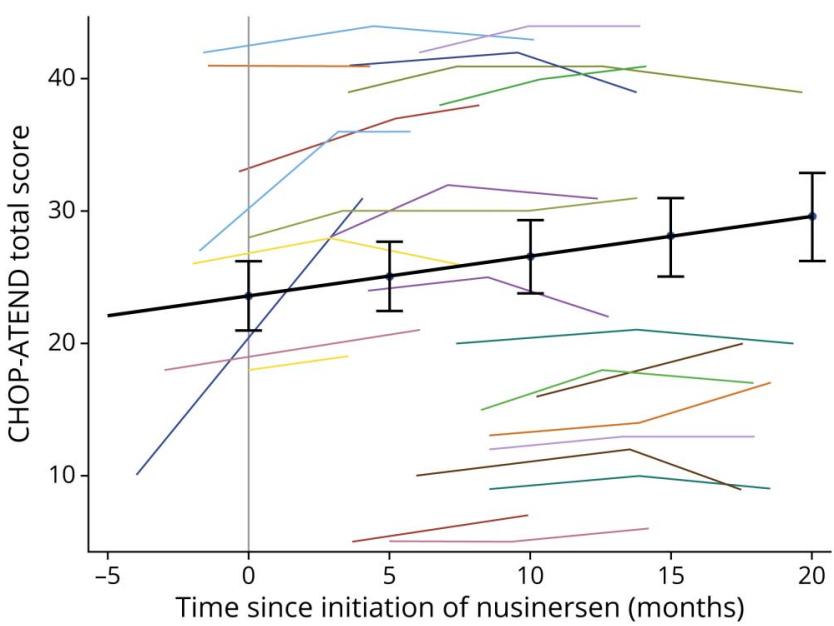

Children's Hospital of Philadelphia Adult Test for Neuromuscular Disorders (CHOP-ATEND) results for the entire population studied $(n=24)$ Individual subject trajectories are shown. The dark line (with standard error bars) depicts the average trajectory, as estimated from a linear mixed-effects model. per year. ${ }^{35}$ Unlike the recent publication performed by 10 clinical sites in Germany, none of the subgroups or functional cohorts we analyzed had a significant 3 point improvement on the HFMSE. $^{36}$ This may be due to our small sample size and the heterogeneity of our cohort (range of $0-60$ points on the HFMSE, figure 3). Patients with SMA with long-standing spinal fusions have greater truncal stability, ventilatory ability, and upper limb function with fewer compensatory mechanisms; despite a wide $\mathrm{CI}$, our observation of improved respiratory function and RULM responses with nusinersen in adults with spinal fusions were consistent with the German study. ${ }^{36}$

Insurance approvals for nusinersen treatment may be varied for individuals with 4 copies of SMN2. Our study highlights a heterogeneous group of 9 adults with 4 copies of $S M N 2$ including 4 participants with SMA type 2/3 classified as nonsitters and 5 participants with SMA type 3 classified as ambulatory. Despite inherent flaws in accurately ascertaining symptom onset in the adult population, disease duration should be monitored as a phenotypic feature that may clarify prognosis and response to treatment for adults with 4 SMN2 copies.

Initial reports regarding tolerability in adults assessed motor function scores before and after loading doses of nusinersen in 28 adults with SMA. They found that nusinersen administration was safe and tolerable, yet unsurprisingly found no significant improvements in the 2-month follow-up period. ${ }^{31}$ Initial real-world studies reported on a cohort of 19 adults treated for up to 10 months and found improvements in the 6MWT and RULM, but no significant changes in other measures. ${ }^{37}$ Compared with our study, their patient cohort was functionally stronger with $63 \%$ being ambulatory compared with only $26 \%$ in our study. Similar to our findings, there were no significant changes in FVC; however, they found significant improvements in peak cough, which 
Table 3 Average Rates of Change per Year in Outcome Measures in Participant Subgroups

\begin{tabular}{|c|c|c|c|}
\hline Outcome & $\mathrm{N}$ & Slope $^{a}$ & $95 \% \mathrm{Cl}$ \\
\hline \multicolumn{4}{|l|}{ HFMSE } \\
\hline Type 2 & 11 & 0.66 & -1.63 to 2.95 \\
\hline Type 3 & 20 & 0.99 & -0.77 to 2.74 \\
\hline 3 SMN2 copies & 18 & 0.55 & -0.97 to 2.06 \\
\hline 4 SMN2 copies & 7 & -0.15 & -2.41 to 2.10 \\
\hline Nonsitter & 9 & -0.24 & -3.57 to 3.09 \\
\hline Sitter & 11 & 1.13 & -1.11 to 3.36 \\
\hline Walker & 11 & 1.09 & -1.26 to 3.44 \\
\hline No spinal fusion & 21 & 1.24 & -0.53 to 3.01 \\
\hline Spinal fusion & 10 & 0.13 & -2.21 to 2.47 \\
\hline \multicolumn{4}{|l|}{ RULM } \\
\hline Type 2 & 16 & 0.43 & -0.44 to 1.31 \\
\hline Type 3 & 23 & -0.12 & -0.81 to 0.57 \\
\hline 3 SMN2 copies & 24 & 0.22 & -0.41 to 0.85 \\
\hline 4 SMN2 copies & 8 & -0.23 & -1.11 to 0.66 \\
\hline Nonsitter & 16 & -0.17 & -1.09 to 0.74 \\
\hline Sitter & 12 & 0.74 & -0.32 to 1.80 \\
\hline Walker & 11 & -0.01 & -1.02 to 0.99 \\
\hline No spinal fusion & 25 & -0.22 & -0.77 to 0.33 \\
\hline Spinal fusion & 14 & 1.01 & 0.03 to 1.98 \\
\hline \multicolumn{4}{|l|}{ SMAFRS } \\
\hline Type 2 & 12 & 0.74 & -1.57 to 3.06 \\
\hline Type 3 & 19 & 1.89 & 0.21 to 3.58 \\
\hline 3 SMN2 copies & 19 & 1.32 & -0.37 to 3.02 \\
\hline 4 SMN2 copies & 8 & 0.43 & -1.81 to 2.66 \\
\hline Nonsitter & 13 & 0.69 & -1.67 to 3.04 \\
\hline Sitter & 9 & 2.88 & 0.56 to 5.19 \\
\hline Walker & 9 & 0.51 & -1.98 to 3.00 \\
\hline No spinal fusion & 23 & 1.28 & -0.35 to 2.91 \\
\hline Spinal fusion & 8 & 1.85 & -1.06 to 4.77 \\
\hline \multicolumn{4}{|l|}{ CHOP-ATEND } \\
\hline Type 2 & 14 & 3.75 & -0.16 to 7.66 \\
\hline Type 3 & 10 & 3.26 & -1.34 to 7.86 \\
\hline 3 SMN2 copies & 18 & 3.62 & -0.10 to 7.35 \\
\hline 4 SMN2 copies & 3 & 3.05 & -5.96 to 12.05 \\
\hline Nonsitter & 15 & 6.44 & 2.25 to 10.62 \\
\hline Sitter & 9 & -0.29 & -5.07 to 4.50 \\
\hline No spinal fusion & 14 & 3.12 & -0.77 to 7.01 \\
\hline
\end{tabular}


Table 3 Average Rates of Change per Year in Outcome Measures in Participant Subgroups (continued)

\begin{tabular}{|c|c|c|c|}
\hline Outcome & $\mathrm{N}$ & Slope ${ }^{a}$ & $95 \% \mathrm{Cl}$ \\
\hline Spinal fusion & 10 & 4.41 & -0.25 to 9.07 \\
\hline \multicolumn{4}{|l|}{ FVC (\%) } \\
\hline Type 2 & 11 & 2.61 & -1.66 to 6.89 \\
\hline Type 3 & 16 & -0.31 & -3.65 to 3.04 \\
\hline 3 SMN2 copies & 18 & 1.81 & -2.06 to 5.68 \\
\hline 4 SMN2 copies & 7 & -2.13 & -7.50 to 3.25 \\
\hline Nonsitter & 11 & 1.36 & -2.31 to 5.03 \\
\hline Sitter & 11 & 2.25 & -2.33 to 6.83 \\
\hline Walker & 5 & -1.97 & -7.78 to 3.85 \\
\hline No spinal fusion & 16 & -1.03 & -4.14 to 2.09 \\
\hline Spinal fusion & 11 & 5.31 & 0.36 to 10.25 \\
\hline \multicolumn{4}{|l|}{ MEP $\left(\mathrm{cm} \mathrm{H}_{2} \mathrm{O}\right)$} \\
\hline Nonsitter & 10 & 1.95 & -4.84 to 8.74 \\
\hline Sitter & 10 & 3.92 & -4.54 to 12.38 \\
\hline Walker & 5 & 18.25 & 6.86 to 29.64 \\
\hline No spinal fusion & 16 & 7.68 & 2.23 to 13.12 \\
\hline Spinal fusion & 9 & 3.61 & -4.38 to 11.59 \\
\hline \multicolumn{4}{|l|}{ MIP (cm H} \\
\hline Type 2 & 11 & -4.34 & -13.68 to 4.99 \\
\hline Type 3 & 15 & -6.27 & -13.82 to 1.28 \\
\hline 3 SMN2 copies & 18 & -1.88 & -8.73 to 4.97 \\
\hline 4 SMN2 copies & 6 & -8.67 & -17.91 to 0.58 \\
\hline Nonsitter & 11 & -7.63 & -16.83 to 1.58 \\
\hline Sitter & 10 & -1.12 & -12.04 to 9.81 \\
\hline Walker & 5 & -7.79 & -22.42 to 6.83 \\
\hline No spinal fusion & 16 & -4.51 & -11.81 to 2.78 \\
\hline Spinal fusion & 10 & -6.74 & -18.12 to 4.64 \\
\hline
\end{tabular}

Abbreviations: 6MWT = 6-minute walk test; CHOP-ATEND = Children's Hospital of Philadelphia Adult Test for Neuromuscular Disorders; Cl = confidence interval; FVC = forced vital capacity; HFMSE = Hammersmith Functional Motor Scale Expanded; MEP = maximal expiratory pressure; MIP = maximal inspiratory pressure; RULM = Revised Upper Limb Module; SMAFRS = SMA Functional Rating Scale; TUG = timed up and go.

a Slope is expressed as the unit change in outcome per year.

parallels the improved MEP that was found to be a sensitive indicator of change in our study. Studies have shown that peak cough is correlated with MIP and $\mathrm{MEP}^{38}$ and that MEP plays an important role in peak cough ability. ${ }^{39}$ More recently, a larger German cohort reported on 139 participants indicating efficacy in treatment using HFMSE, RULM, and $6 \mathrm{MWT} .{ }^{36}$ Comparing our patient cohorts, individuals in our study had a more varied and severe phenotype with $38 \%$ spinal fusion compared with $25 \%$, and $14 \%$ more individuals who were nonambulatory.
The primary limitation of this study is the lack of a concurrent control group as all patients in our clinics were treated with nusinersen. Selection bias may be present because patients unable to tolerate intrathecal treatments are also most likely to be severely affected with scoliosis. The lack of blinding is an especially noteworthy limitation to this study, but because the FDA approved nusinersen for individuals of all ages affected by SMA, a randomized placebo-controlled trial is no longer feasible for any population of patients with SMA in the United States. It is possible that the observed improvements in our study could be ascribed, at least in 
Figure 3 HFMSE Total Score Trajectories Based on Functional Status

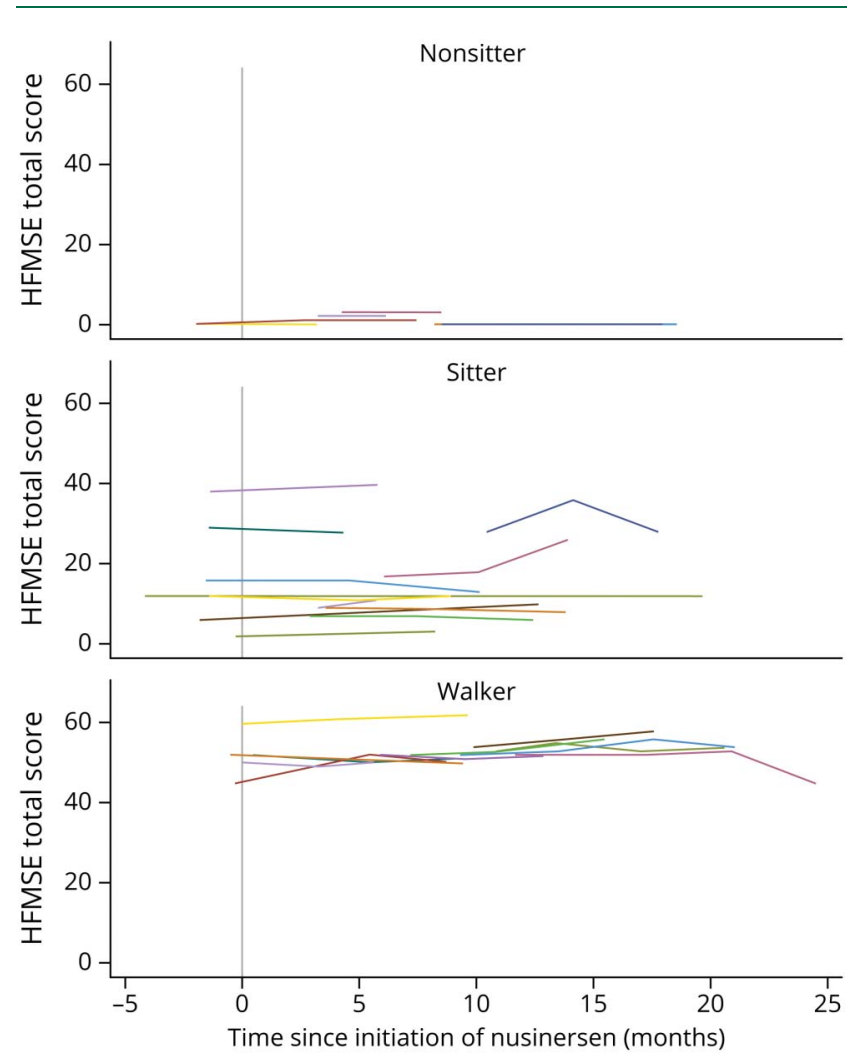

Hammersmith Functional Motor Scale Expanded (HFMSE) results for entire population studied $(n=31)$ grouped by functional status at baseline: nonsitters $(n=9)$, sitters $(n=11)$, and walkers $(n=11)$.

part, to placebo effects or a learning curve of the assessments. Longer follow-up will be valuable to assess durability of the response, which is more likely for biological than placebo effects of treatment. Furthermore, subgroup analyses were limited by the relatively small number of patients and the broad range of their functional abilities, which can only be addressed by longitudinal assessments of more adult patients on nusinersen, or other SMN restoring treatments.

Other limitations resulted from variable timing of and circumstances surrounding evaluations. Forty-three percent of participants had evaluations on the same day of injections, and only 1 participant had a 1 -week delay in dosing. For these reasons, the real-world data obtained in this study are inherently more variable than the published data of nusinersen's effects on infantile- and juvenile-onset patients in more structured randomized controlled trials.

This study attempts to fill some of the knowledge gaps identified in nusinersen treatment of SMA, ${ }^{40}$ which included more severely weak individuals than is true of currently published studies of nusinersen in adults with SMA. The high cost of treatment associated with nusinersen is a consideration that must be addressed particularly in a value to health care-based system. Typical motor outcome measures used in clinical trials may not show improvements in this older more heterogeneous population. Given the range of subjective improvements reported by participants in this study, future directions should focus on development and validation of novel outcome measures that may better assess treatment responses, such as patient-reported outcome measures; measures of endurance and fatigability; measures of bulbar function including voice, speech, swallow, jaw, or tongue movement; and measures of trunk and neck movements. Quantification of these features in the severely and chronically weak adults may be more responsive to the effects of interventions. Careful clinical guidance should be considered in the management of expectation for older individuals as efficacy may be affected by other clinical factors such as disease duration, contractures, spinal fusions, and adherence to standards of care.

Although improved motor function is always a goal of treatment, stabilization of the otherwise progressively declining disease course of SMA would itself be of tremendous benefit to individuals affected by this chronic degenerative disorder. Stabilization and improvement of respiratory function is also of value to this population for whom respiratory infection is a considerable cause of morbidity and mortality. Ongoing studies of nusinersen, and development of biomarkers and novel outcome measures that can more completely ascertain response to treatment, will be important to confirm and extend the results of this initial study and to provide greater understanding of the changing natural history of adults with SMA in this new era of genetic treatments. These measures will also help determine when the cellular pathophysiology of SMA has been controlled and will help define unmet needs in the adult SMA population that can be addressed with approaches complementary to SMN protein restoration.

\section{Acknowledgment}

This work would not have been possible without the support of the Spinal Muscular Atrophy Foundation and the PNCR network. The authors thankfully acknowledge the families and patients who dedicated their time to participate in this study.

\section{Study Funding}

The study was supported by the SMA Foundation and Cure SMA.

\section{Disclosure}

T. Duong has been an advisory board member of Cure SMA, Biogen, Cytokinetics, Roche, Scholar Rock, Sarepta, Bristol Myers Squibb, Audentes, and Novartis and served as a consultant for Roche, Audentes, and Novartis. C. Wolford and C.E. Macpherson report no disclosures relevant to the manuscript. M.P. McDermott has received research support from the NIH, FDA, SMA Foundation, Cure SMA, and PTC Therapeutics; served as a consultant for Fulcrum Therapeutics, Inc.; and served on Data and Safety Monitoring Boards for NIH, AstraZeneca, Eli Lilly and Company, Catabasis Pharmaceuticals, Inc., Vaccinex, Inc., Cynapsus Therapeutics, Voyager Therapeutics, and Prilenia Therapeutics Development, Ltd. A Pasternak has been an advisory board member of Biogen, Roche, Scholar Rock, and Audentes; served as a consultant for Scholar 
Rock and Audentes; and received research support from the SMA Foundation. A.M. Glanzman receives institutional support from AveXis, Biogen, and Roche for trial training and/or outcome measure review and compensation from ATOM International for trial training; Aspa Therapeutics for outcomes consulting and Audentes Therapeutics for outcome review; Biogen advisory board; and licensing fees from CHOP-INTEND. W. Martens reports no disclosures relevant to the manuscript. E.A. Kichula has been an advisory board member for Biogen, Roche, AveXis, PTC Therapeutics, and Stealth. B.T. Darras has been a member of advisory boards for AveXis, Biogen, Vertex, Cytokinetics, Roche, Genentech, and Sarepta; has received research support from the $\mathrm{NIH} /$ National Institute of Neurologic Disorders and Stroke, the Slaney Family Fund for SMA, the SMA Foundation, and the Working on Walking Fund; has received grants from Biogen, CureSMA, and Ionis Pharmaceuticals, Inc. during the ENDEAR, CHERISH, CS2, CS12, and CS11 studies, and from AveXis, Cytokinetics, Fibrogen, PTC, Roche, Santhera, Sarepta, and Summit; and reports no personal financial interests in these companies. D. De Vivo has been an advisor/consultant for AveXis, Biogen, Cytokinetics, Ionis Pharmaceuticals, Inc., Metafora, Roche, Sanofi, Sarepta, and the SMA Foundation, with no financial interests in these companies; received grants from the Department of Defense, Hope for Children Research Foundation, the NIH, and the SMA Foundation; and received clinical trial funding from Biogen, Mallinckrodt, PTC, Sarepta, Scholar Rock, and Ultragenyx. Z. Zolkipli-Cunningham has received research support from the SMA Foundation (PNCR network for SMA, site PI), and Biogen. Stroke, the Slaney Family Fund for SMA, the SMA Foundation, and the Working on Walking Fund; has received grants from Biogen. R. Finkel served as a Data and Safety Monitoring Board (DSMB) member for the eteplirsen Duchenne MD trial sponsored by Sarepta Therapeutics, the START gene therapy clinical trial at Nationwide Children's Hospital, and the MOONFISH risdiplam trial sponsored by Roche; serves on medical/scientific advisory boards for AveXis, Biogen, BMS, Catabasis, Capricor, DuchenneConnect, Eli Lilly, Families of SMA, PTC Therapeutics, Inc., Ionis Pharmaceuticals, Neurogene, Novartis, Roche, Sarepta, SMA-REACH, and Summit; serves on the editorial board of Neuromuscular Disorders and Journal of Neuromuscular Disorders and is a coeditor of the 6th edition of Swaiman's Pediatric neurology text; receives research support from AveXis, Biogen, BMS, Capricor, Catabasis, Eli Lilly, Ionis Pharmaceuticals, Inc., PTC Therapeutics, IncReveraGen, Roche, Santhera Pharmaceuticals, Scholar Rock, Summit, the NIH Cure SMA, the SMA Foundation, the Muscular Dystrophy Association, Genzyme Corporation, and the Charcot-Marie-Tooth Association; receives licensing fees for the CHOP-INTEND from Children's Hospital of Philadelphia; and his spouse serves on the editorial board of Arthritis Research and Therapy, holds and has received license fees for numerous patents related to T-cell activation and HIV, and receives research support from the Gates Foundation, Merck Serono, and the NIH in the field of T-cell activation, HIV, and genomics of juvenile arthritis. M. Zeinheh, M. Wintermark, K.A. Hagerman, and J. Sampson report no disclosures relevant to the manuscript. S. Dunaway Young has been an advisory board member for Biogen, Roche/Genentech, and

\section{TAKE-HOME POINTS}

$\rightarrow$ This natural history study of nusinersen in adults identifies different responses to treatment in the real-world setting.

$\rightarrow$ Nusinersen is safe, feasible, and well tolerated in adults with SMA.

$\rightarrow$ Initial results show an emerging positive trend in both motor and respiratory function in a heterogeneous cohort, including severely weak adults, contrary to the natural history.

$\rightarrow$ Future studies must address unmet needs pertaining to patient-reported outcomes, endurance, bulbar function, and motor assessments for those who are very weak and contracted to better understand the impact of changes with nusinersen and complementary approaches to SMN protein restoration.

Scholar Rock; received personal compensation for activities with Biogen, Cure SMA, Scholar Rock, and Roche/Genentech as a consultant; and received research support from the SMA Foundation. J.W. Day has received consulting fees from Audentes, Biogen, Ionis Pharmaceuticals, Roche/Genentech Pharmaceuticals, Cytokinetics, Pfizer, AveXis, AMO Pharmaceuticals, Sarepta Therapeutics, Santhera Pharmaceuticals, and Scholar Rock. He has received grant support from Biogen; Ionis Pharmaceuticals, Cytokinetics, Roche Pharmaceuticals, AveXis, Sanofi-Genzyme, Sarepta Therapeutics, and Scholar Rock. Full disclosure form information provided by the authors is available with the full text of this article at Neurology.org/cp.

\section{Publication History}

Received by Neurology: Clinical Practice April 9, 2020. Accepted in final form November 3, 2020.

\section{Appendix 1 Authors}

\begin{tabular}{lll}
\hline Name & Location & Contribution \\
\hline Tina Duong, PT, PhD & $\begin{array}{l}\text { Stanford University, } \\
\text { Palo Alto, CA }\end{array}$ & $\begin{array}{l}\text { Designed and } \\
\text { conceptualized the } \\
\text { study; major role in } \\
\text { acquisition of data; } \\
\text { analyzed and } \\
\end{array}$ \\
& $\begin{array}{l}\text { interpreted data; and } \\
\text { drafted and revised the } \\
\text { manuscript for } \\
\text { intellectual content }\end{array}$ \\
\end{tabular}

Connie Wolford, MSN, Stanford University, Designed and FNP-BC Palo Alto, CA conceptualized the study; major role in acquisition of data; analyzed and interpreted data; and revised the manuscript for intellectual content 
Appendix 1 (continued)

\begin{tabular}{|c|c|c|}
\hline Name & Location & Contribution \\
\hline $\begin{array}{l}\text { Michael P. } \\
\text { McDermott, PhD }\end{array}$ & $\begin{array}{l}\text { University of Rochester, } \\
\text { New York }\end{array}$ & $\begin{array}{l}\text { Performed } \\
\text { biostatistical analysis of } \\
\text { results; interpreted the } \\
\text { data; and revised the } \\
\text { manuscript for } \\
\text { intellectual content }\end{array}$ \\
\hline $\begin{array}{l}\text { Chelsea E. } \\
\text { Macpherson, PT, DPT, } \\
\text { NCS }\end{array}$ & $\begin{array}{l}\text { Stanford University, } \\
\text { Palo Alto, CA }\end{array}$ & $\begin{array}{l}\text { Major role in the } \\
\text { acquisition of data and } \\
\text { revised the manuscript } \\
\text { for intellectual content }\end{array}$ \\
\hline $\begin{array}{l}\text { Amy Pasternak, PT, } \\
\text { DPT, PCS }\end{array}$ & $\begin{array}{l}\text { Boston Children's } \\
\text { Hospital, MA }\end{array}$ & $\begin{array}{l}\text { Designed and } \\
\text { conceptualized the } \\
\text { study; major role in } \\
\text { acquisition of data; } \\
\text { analyzed and } \\
\text { interpreted data; and } \\
\text { revised the manuscript } \\
\text { for intellectual content }\end{array}$ \\
\hline $\begin{array}{l}\text { Allan M. Glanzman, } \\
\text { PT, DPT, PCS }\end{array}$ & $\begin{array}{l}\text { Children's Hospital of } \\
\text { Philadelphia, PA }\end{array}$ & $\begin{array}{l}\text { Designed and } \\
\text { conceptualized the } \\
\text { study; major role in } \\
\text { acquisition of data; } \\
\text { analyzed and } \\
\text { interpreted data; and } \\
\text { revised the manuscript } \\
\text { for intellectual content }\end{array}$ \\
\hline
\end{tabular}

\section{William B. Martens, University of Rochester, Performed}

BA

New York

biostatistical review of results; interpreted the data; and revised the manuscript for intellectual content

\begin{tabular}{ll}
\hline Elizabeth A. Kichula, & Children's Hospital of \\
MD, BA & Philadelphia, PA
\end{tabular}

Designed and conceptualized the study and revised the manuscript for intellectual content

\begin{tabular}{|c|c|c|}
\hline Basil Darras, MD & $\begin{array}{l}\text { Boston Children's } \\
\text { Hospital, MA }\end{array}$ & $\begin{array}{l}\text { Designed and } \\
\text { conceptualized the } \\
\text { study and revised the } \\
\text { manuscript for } \\
\text { intellectual content }\end{array}$ \\
\hline
\end{tabular}

\begin{tabular}{lll}
\hline Darryl C. De Vivo, MD & $\begin{array}{l}\text { Columbia University } \\
\text { Medical Center, New } \\
\text { York }\end{array}$ & $\begin{array}{l}\text { Designed and } \\
\text { conceptualized the } \\
\text { study and revised the } \\
\text { manuscript for } \\
\text { intellectual content }\end{array}$ \\
\hline $\begin{array}{l}\text { Zarazuela Zolkipli- } \\
\text { Cunningham, MBChB, } \\
\text { MRCP }\end{array}$ & $\begin{array}{l}\text { Children's Hospital of } \\
\text { Philadelphia, PA }\end{array}$ & $\begin{array}{l}\text { Designed and } \\
\text { conceptualized the } \\
\text { study and revised the } \\
\text { manuscript for } \\
\text { intellectual content }\end{array}$ \\
\hline Richard Finkel, MD & Nemours, Orlando, FL & $\begin{array}{l}\text { Designed and } \\
\text { conceptualized the } \\
\text { study and revised the } \\
\text { manuscript for } \\
\text { intellectual content }\end{array}$ \\
& &
\end{tabular}

\begin{tabular}{lll}
\hline Michael Zeineh, MD, & Stanford University, & Major role in the \\
PhD & Palo Alto, CA & $\begin{array}{l}\text { acquisition of data and } \\
\text { revised the manuscript }\end{array}$ \\
&
\end{tabular}

\begin{tabular}{lll}
\hline Max Wintermark, MD & $\begin{array}{l}\text { Stanford University, } \\
\text { Palo Alto, CA }\end{array}$ & $\begin{array}{l}\text { Major role in the } \\
\text { acquisition of data and } \\
\text { revised the manuscript } \\
\text { for intellectual content }\end{array}$
\end{tabular}

Appendix 1 (continued)

\begin{tabular}{|c|c|c|}
\hline Name & Location & Contribution \\
\hline $\begin{array}{l}\text { Katharine A. } \\
\text { Hagerman, PhD }\end{array}$ & $\begin{array}{l}\text { Stanford University, } \\
\text { Palo Alto, CA }\end{array}$ & $\begin{array}{l}\text { Major role in } \\
\text { acquisition of data; } \\
\text { analyzed and } \\
\text { interpreted data; and } \\
\text { revised the manuscript } \\
\text { for intellectual content }\end{array}$ \\
\hline $\begin{array}{l}\text { Jacinda Sampson, MD, } \\
\text { PhD }\end{array}$ & $\begin{array}{l}\text { Stanford University, } \\
\text { Palo Alto, CA }\end{array}$ & $\begin{array}{l}\text { Designed and } \\
\text { conceptualized the } \\
\text { study and revised the } \\
\text { manuscript for } \\
\text { intellectual content }\end{array}$ \\
\hline $\begin{array}{l}\text { Sally Dunaway Young, } \\
\text { PT, DPT }\end{array}$ & $\begin{array}{l}\text { Stanford University, } \\
\text { Palo Alto, CA }\end{array}$ & $\begin{array}{l}\text { Designed and } \\
\text { conceptualized the } \\
\text { study; major role in } \\
\text { acquisition of data; } \\
\text { analyzed and } \\
\text { interpreted data; and } \\
\text { drafted and revised the } \\
\text { manuscript for } \\
\text { intellectual content }\end{array}$ \\
\hline John W. Day, MD, PhD & $\begin{array}{l}\text { Stanford University, } \\
\text { Palo Alto, CA }\end{array}$ & $\begin{array}{l}\text { Designed and } \\
\text { conceptualized the } \\
\text { study; analyzed and } \\
\text { interpreted data; and } \\
\text { drafted and revised the } \\
\text { manuscript for } \\
\text { intellectual content }\end{array}$ \\
\hline
\end{tabular}

\section{Appendix 2 Coinvestigators}

Coinvestigators from the Stanford Neuromuscular Coordinating Center are listed below.

\begin{tabular}{|c|c|c|c|}
\hline Name & Location & Role & Contribution \\
\hline $\begin{array}{l}\text { Shirley } \\
\text { Paulose }\end{array}$ & $\begin{array}{l}\text { Stanford } \\
\text { University, Palo } \\
\text { Alto, CA }\end{array}$ & Coinvestigator & $\begin{array}{l}\text { Led and coordinated } \\
\text { communication among } \\
\text { the study }\end{array}$ \\
\hline $\begin{array}{l}\text { Lesly } \\
\text { Welsh }\end{array}$ & $\begin{array}{l}\text { Stanford } \\
\text { University, Palo } \\
\text { Alto, CA }\end{array}$ & Coinvestigator & Coordinated study visits \\
\hline $\begin{array}{l}\text { Whitney } \\
\text { Tang }\end{array}$ & $\begin{array}{l}\text { Stanford } \\
\text { University, Palo } \\
\text { Alto, CA }\end{array}$ & Coinvestigator & $\begin{array}{l}\text { Data entry and } \\
\text { management }\end{array}$ \\
\hline $\begin{array}{l}\text { Rachel } \\
\text { Salazar }\end{array}$ & $\begin{array}{l}\text { Columbia } \\
\text { University, New } \\
\text { York }\end{array}$ & Coinvestigator & $\begin{array}{l}\text { Performed Clinical } \\
\text { evaluations }\end{array}$ \\
\hline
\end{tabular}

\section{References}

1. Vill K, Kolbel H, Schwartz O, et al. One year of newborn screening for SMA - results of a German pilot project. J Neuromuscular Diseases 2019;6:503-515.

2. Darras BTMJ, Monani UR, De Vivo DC. Neuromuscular disorders of infancy, childhood, and adolescence. San Diego: Academic Press; 2015.

3. Darras BT, De Vivo DC. Precious SMA natural history data: a benchmark to measure future treatment successes. Neurology 2018;91:337-339.

4. Kolb SJ, Coffey CS, Yankey JW, et al. Natural history of infantile-onset spinal muscular atrophy. Ann Neurology 2017;82:883-891.

5. Bergin A, Kim G, Price DL, Sisodia SS, Lee MK, Rabin BA. Identification and characterization of a mouse homologue of the spinal muscular atrophy-determining gene, survival motor neuron. Gene 1997;204:47-53.

6. Wirth B, Hahnen E, Morgan K, et al. Allelic association and deletions in autosomal recessive proximal spinal muscular atrophy: association of marker genotype with disease severity and candidate cDNAs. Hum Molecular Genetics 1995;4: $1273-1284$. 
7. Hua Y, Sahashi K, Rigo F, et al. Peripheral SMN restoration is essential for longterm rescue of a severe spinal muscular atrophy mouse model. Nature $2011 ; 478$ $123-126$.

8. Rigo F, Hua Y, Krainer AR, Bennett CF. Antisense-based therapy for the treatment of spinal muscular atrophy. J Cel Biol 2012;199:21-25.

9. Darras BT, Chiriboga CA, Iannaccone ST, et al. Nusinersen in later-onset spinal muscular atrophy: long-term results from the phase $1 / 2$ studies. Neurology 2019;92: e2492-e2506.

10. Montes J, Dunaway Young S, Mazzone ES, et al. Nusinersen improves walking distance and reduces fatigue in later-onset spinal muscular atrophy. Muscle \& Nerve 2019;60:409-414.

11. Mercuri E, Darras BT, Chiriboga CA, et al. Nusinersen versus sham control in lateronset spinal muscular atrophy. New Engl Journal Medicine 2018;378:625-635.

12. Chiriboga CA, Swoboda KJ, Darras BT, et al. Results from a phase 1 study of nusinersen (ISIS-SMN $(\mathrm{Rx})$ ) in children with spinal muscular atrophy. Neurology 2016; 86:890-897.

13. Pane M, Palermo C, Messina S, et al. Nusinersen in type 1 SMA infants, children and young adults: preliminary results on motor function. Neuromuscul Disorders : NMD 2018;28:582-585.

14. Finkel RS, Mercuri E, Darras BT, et al. Nusinersen versus sham control in infantileonset spinal muscular atrophy. New Engl Journal Medicine 2017;377:1723-1732.

15. Finkel RS, Chiriboga CA, Vajsar J, et al. Treatment of infantile-onset spinal muscular atrophy with nusinersen: a phase 2, open-label, dose-escalation study. Lancet 2016, 388:3017-3026.

16. Kaufmann P, McDermott MP, Darras BT, et al. Prospective cohort study of spinal muscular atrophy types 2 and 3. Neurology 2012;79:1889-1897.

17. Kaufmann P, McDermott MP, Darras BT, et al. Observational study of spinal muscular atrophy type 2 and 3: functional outcomes over 1 year. Arch Neurol 2011;68: 779-786.

18. Finkel RS, McDermott MP, Kaufmann P, et al. Observational study of spinal muscular atrophy type I and implications for clinical trials. Neurology 2014;83:810-817.

19. Pera MC, Coratti G, Mazzone ES, et al. Revised upper limb module for spinal muscular atrophy: 12 month changes. Muscle \& Nerve 2019;59:426-430.

20. Mercuri E, Finkel R, Montes J, et al. Patterns of disease progression in type 2 and 3 SMA: implications for clinical trials. Neuromuscul Disorders 2016;26:126-131.

21. Montes J, McDermott MP, Mirek E, et al. Ambulatory function in spinal muscular atrophy: age-related patterns of progression. PloS One 2018;13:e0199657.

22. Wadman RI, Wijngaarde CA, Stam M, et al. Muscle strength and motor function throughout life in a cross-sectional cohort of 180 patients with spinal muscular atrophy types 1c-4. Eur J Neurol 2018;25:512-518.

23. Wijngaarde CA, Blank AC, Stam M, Wadman RI, van den Berg LH, van der Pol WL. Cardiac pathology in spinal muscular atrophy: a systematic review. Orphanet Journal Rare Diseases 2017;12:67.

24. Kichula E, Duong T, Glanzman A, et al. J. Children's hospital of Philadelphia infant test of neuromuscular disorders (CHOP INTEND) feasibility for individuals with severe spinal muscular atrophy II. Neurology 2018;90 (15 Supplement).
25. Glanzman AM, McDermott MP, Montes J, et al. Validation of the Children's hospital of Philadelphia infant test of neuromuscular disorders (CHOP INTEND). Pediatr Phys Ther 2011;23:322-326.

26. Elsheikh B, Prior T, Zhang X, et al. An analysis of disease severity based on SMN2 copy number in adults with spinal muscular atrophy. Muscle \& Nerve 2009;40. $652-656$.

27. Glanzman AM, O'Hagen JM, McDermott MP, et al. Validation of the expanded Hammersmith functional motor scale in spinal muscular atrophy type II and III. J Child Neurology 2011;26:1499-1507.

28. Mazzone ES, Mayhew A, Montes J, et al. Revised upper limb module for spinal muscular atrophy: development of a new module. Muscle \& Nerve 2017;55:869-874.

29. Dunaway S, Montes J, Garber CE, et al. Performance of the timed "up \& go" test in spinal muscular atrophy. Muscle \& Nerve 2014;50:273-277.

30. Nath S, Koziarz A, Badhiwala JH, et al. Atraumatic versus conventional lumbar puncture needles: a systematic review and meta-analysis. Lancet 2018;391: $1197-1204$

31. Stolte B, Totzeck A, Kizina K, et al. Feasibility and safety of intrathecal treatment with nusinersen in adult patients with spinal muscular atrophy. Ther Adv Neurol Disord 2018;11:1756286418803246.

32. Wurster CD, Gunther R, Steinacker P, et al. Neurochemical markers in CSF of adolescent and adult SMA patients undergoing nusinersen treatment. Ther Adv Neurol Disord 2019;12:1756286419846058.

33. Veerapandiyan A, Eichinger K, Guntrum D, et al. Nusinersen for older patients with spinal muscular atrophy: a real-world clinical setting experience. Muscle \& Nerve 2019;61:222-226

34. Wadman RI, van Bruggen HW, Witkamp TD, et al. Bulbar muscle MRI changes in patients with SMA with reduced mouth opening and dysphagia. Neurology 2014;83: 1060-1066.

35. Kaufmann P, McDermott MP, Darras BT, et al. Observational study of spinal muscular atrophy type 2 and 3: functional outcomes over 1 year. Arch Neurology 2011;68 779-786.

36. Hagenacker $T$, Wurster CD, Günther R, et al. Nusinersen in adults with $5 q$ spinal muscular atrophy: a non-interventional, multicentre, observational cohort study. Lancet Neurol 2020;19:317-325.

37. Walter MC, Wenninger S, Thiele S, et al. Safety and treatment effects of nusinersen in longstanding adult 5q-SMA type 3 - a prospective observational study.J Neuromuscular Diseases 2019;6:453-465.

38. Park JH, Kang SW, Lee SC, Choi WA, Kim DH. How respiratory muscle strength correlates with cough capacity in patients with respiratory muscle weakness. Yonsei Med J 2010;51:392-397.

39. Jo MR, Kim NS. The correlation of respiratory muscle strength and cough capacity in stroke patients. J Phys Ther Sci 2016;28:2803-2805.

40. Gidaro T, Servais L. Nusinersen treatment of spinal muscular atrophy: current knowledge and existing gaps. Developmental Medicine Child Neurology 2019;61: $19-24$. 


\section{Neurology ${ }^{\circ}$ Clinical Practice}

Nusinersen Treatment in Adults With Spinal Muscular Atrophy

Tina Duong, Connie Wolford, Michael P. McDermott, et al.

Neurol Clin Pract 2021;11;e317-e327 Published Online before print January 25, 2021

DOI 10.1212/CPJ.0000000000001033

This information is current as of January 25, 2021

Updated Information \&
Services

References

Subspecialty Collections

Permissions \& Licensing

Reprints including high resolution figures, can be found at: http://cp.neurology.org/content/11/3/e317.full.html

This article cites 38 articles, 6 of which you can access for free at: http://cp.neurology.org/content/11/3/e317.full.html\#\#ref-list-1

This article, along with others on similar topics, appears in the following collection(s):

All Neuromuscular Disease

http://cp.neurology.org//cgi/collection/all_neuromuscular_disease Anterior nerve cell disease

http://cp.neurology.org//cgi/collection/anterior_nerve_cell_disease Clinical trials Observational study (Cohort, Case control)

http://cp.neurology.org//cgi/collection/clinical_trials_observational_stu dy_cohort_case_control

Information about reproducing this article in parts (figures,tables) or in its entirety can be found online at:

http://cp.neurology.org/misc/about.xhtml\#permissions

Information about ordering reprints can be found online: http://cp.neurology.org/misc/addir.xhtml\#reprintsus

Neurol Clin Pract is an official journal of the American Academy of Neurology. Published continuously since 2011, it is now a bimonthly with 6 issues per year. Copyright Copyright @ 2021 The Author(s). Published by Wolters Kluwer Health, Inc. on behalf of the American Academy of Neurology.. All rights reserved. Print ISSN: 2163-0402. Online ISSN: 2163-0933.

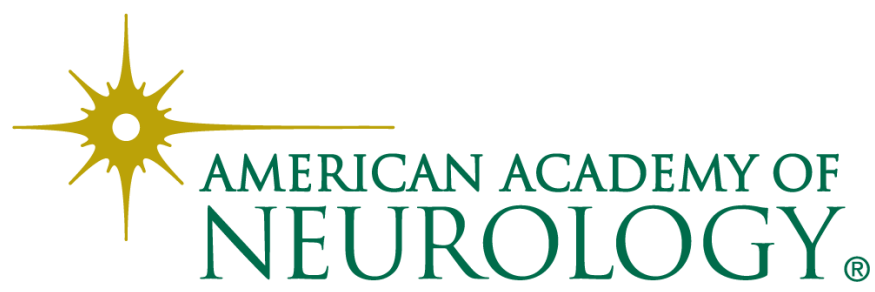

